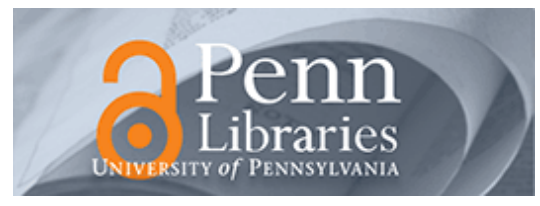

University of Pennsylvania

ScholarlyCommons

Management Papers

Wharton Faculty Research

1979

\title{
Rational Data Base Standards: An Examination of the 1978 CODASYL DDLC Report
}

Eric K. Clemons

University of Pennsylvania

Follow this and additional works at: https://repository.upenn.edu/mgmt_papers

Part of the Management Sciences and Quantitative Methods Commons

\section{Recommended Citation}

Clemons, E. K. (1979). Rational Data Base Standards: An Examination of the 1978 CODASYL DDLC

Report. Information Systems, 4 (3), 2235-239. http://dx.doi.org/10.1016/0306-4379(79)90007-3

This paper is posted at ScholarlyCommons. https://repository.upenn.edu/mgmt_papers/253

For more information, please contact repository@pobox.upenn.edu. 


\title{
Rational Data Base Standards: An Examination of the 1978 CODASYL DDLC Report
}

\author{
Abstract \\ The CODASYL Data Description Language committee's 1978 Report incorporates numerous \\ enhancements and language changes made since the earlier 1971 and 1973 reports. Unfortunately, the \\ major design limitations associated with these earlier specifications, in particular a schema facility too \\ closely related to machine rather than enterprise requirements and an extremely limited subschema \\ facility, are retained. \\ After examination of these limitations, we suggest that the recent CODASYL specifications remain \\ inappropriate as either an instance of an ANSI/SPARC three-schema architecture or as a candidate for a \\ national data base system standard. A long term strategy for the development of a more rational proposal \\ for standardization is suggested. And a short term strategy is offered, one that permits rational planning \\ for and implementation of data base conversions to occur today, without concern that subsequently \\ developed standards might render obsolete the conversion effort and data base management system \\ selected. \\ Disciplines \\ Management Sciences and Quantitative Methods
}




\author{
RATIONAL DATA BASE STANDARDS: \\ AN EXAMINATION OF THE 1978 CODASYL DDLC REPORT
}

\title{
ABSTRACT
}

The CODASYL Data Description Language committee's 1978 Report incorporates numerous enhancements and language changes made since the earlier 1971 and 1973 reports. Unfortunately, the inajor design limitations associated with these earlier specifications, in particular a schema Iacility too closely related to machine rather than enterprise requirements and an extremely ilmited subschema facility, are retained.

After examination of these limitations, we suggest that the recent CODASYL specifications remain inappropriate as either an instance of an ANSI/SPARC three-schema architecture or as a candidate for a national data base system standard. A long term strategy for the development of a more rational proposal for standardization is suggested. And a short term strategy is offered, one that permits rational planning for and implementation of data base conversions to occur today, without concern that subsequently developed standards might render obsolete the conversion effort and data base management system selected.

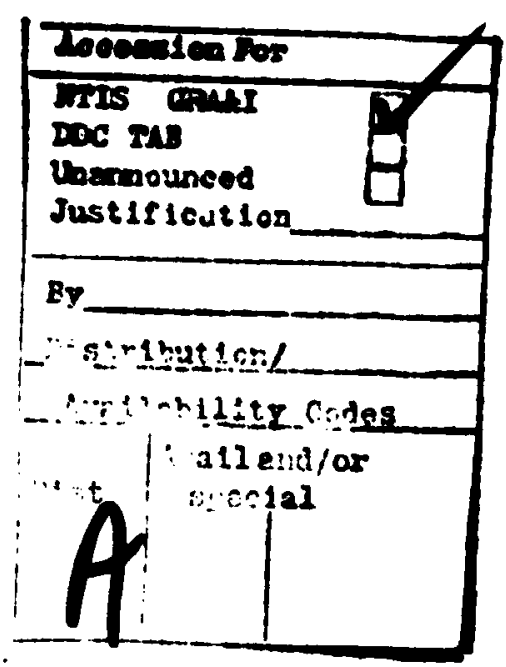


We are addressing two related questions:

1. What is the suitability of the CODASYL 1978 DDL specifications [13] as a candidate for adoption as a national data base system standard?

2. Do these specifications match well with those of the 1975 [1] and 1977 [23] ANSI/X3/SPARC proposals for a three-schema data base architecture?

$\ddot{2}$

I think that many arguments in favor of rapid agreement on a data base standard are clear. Every organization has a large investment in data and data processing software; there is pressure on management to convert to a data base architecture, converting existing data and programs to realize the savings and additional benefits believed to accrue from an integrated data base management system; and it is crucial that the considerable expense associated with this conversion not be wasted by subsequent agreement on a standard that renders obsolete the data base system chosen 14]. Likewise, as users wish to avold the expenses of unnecessary data base conversions, so too do implementors and vendors of data base systems wish to avoid unnecessary modifications and alterations of their products. Indeed, since the 1978 CODASYL specifications differ significantly Irom earlier specifications [19], there is a certain reluctance on the part of some implementors to modify their systems to meet these new specifications, because there is no guarantee that they will remain fixed for a period sufficient to recover conversion costs.

Systems conforming to CODASYL specifications have been chosen by many corporate users; likewise, CODASYL is the ...y model with sufficient vendor support to be considered as a serious candidate for a standard. In fact, the CODASYL specifications are rapidly emerging as a de facto American uata base system standard. I feel very strongly that this is unfortunate; the CODASYL model, in its present form, is largely inappropriate.

Fortunately, there exists an alternative to the premature adoption of a standard: It is only necessary to decide on a "kernel" of a standard, a component of the programmer interface that will be supported in any future data base standard. Here, the CODASYL model fares somewhat better. It is in widespread use, making it a logical cholce. And the ANSI/SPARC proposals which will no doubt have a major influence on future data base management system technology permit great flexibility in any subsequently adopted standards; thus the kernel may be only one of several, dramaticaliy different interfaces supported. Also, 
the low level of the CODASYL data manipulation language and the limited inter-schema mapping facilities supported should make inclusion of a CODASYL interface relatively easy and inexpensive.

\section{SHORTCOMINGS OF CODASYL SPECIFICATIONS}

My principal objection to the CODASYL system is its lack of concern for and support of the programming user. This is not an objection to the design, level, or syntax of the current DML -- if so it would be only a superficial objection -- rather, it is an objection to the form of subschema provided.

The CODASYL system is not appropriate as an instance of the ANSI/SPARC three-schema architecture. It pre-dates the ANSI/SPARC proposal and does not successfully capture its philosophy. While the 1978 DDL specifications include a proposal for a new data storage description language (DSDL) and thus include three schemas, they are not the correct three schemas: The DDL schema is not purely conceptual, but contains constructs better placed in the internal schema as they deal primarily with access efficiency [10]. The subschema facility is even farther from an external schema facility, including both conceptual and internal level constructs. The resulting design is not clean and does not provide adequate separation of functions; this is significant, not because ANSI/SPARC proposal represents an aosolute standard that must be closely followed, but because une limitations of the selected CODASYL design have unfortunate implications for programming ease and programmer productivity, data independence, and distributed processing.

Likewise, I feel that the CODASYL system is not appropriate for adoption as a national data base standard, again because of limitations of the subschema facility and the programing interface. In order to understand the orientation and limitations of the system, it is necessary to remember the period -- late 1960s -- in which its original design and specification were prepared. The principal concerns of the Data Base Task Group were to provide a limited increase in flexibility and generality of uata base systems without incurring substantial penalties in reduced machine efficiency. Thus, networks of associated records provide greater generality than simple hierarchies; by freezing the supported assoclations to be those explicitly declared in sets, flexibility is limited but efficient access is assured. Similarly, by limiting maps between schema and subschemas to a few simple forma, efficient operation is preserved. Unfortunately, the resulting design, while efficient, is too limited; in several ways it is inappropriate for the technology and uemands of contemporary data processing, a decade later and 
in the future.

These limitations stem, principally, from the fact that we subschema follows the schema too closely in form. Individual records in the schema map to single records in une subschema, and data associations remain by set uembership. In general, networks exist in a data base not vecause any single user requires so general a structure, but because the collection of hierarchical associations required by each user are incompatible [7]. Thus, if one user wants a hierarchical association between courses he taught and all student grades for the courses:

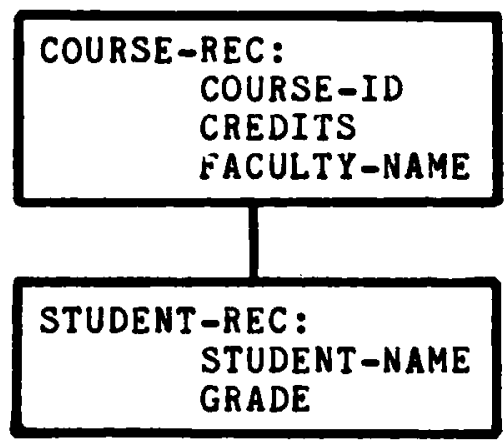

while another user wants a hierarchical association between a student and all course grades received:

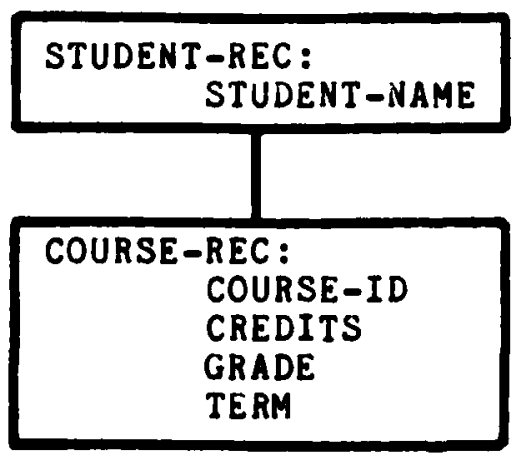

this will probably be captured at the conceptual level with a network of the following form: 


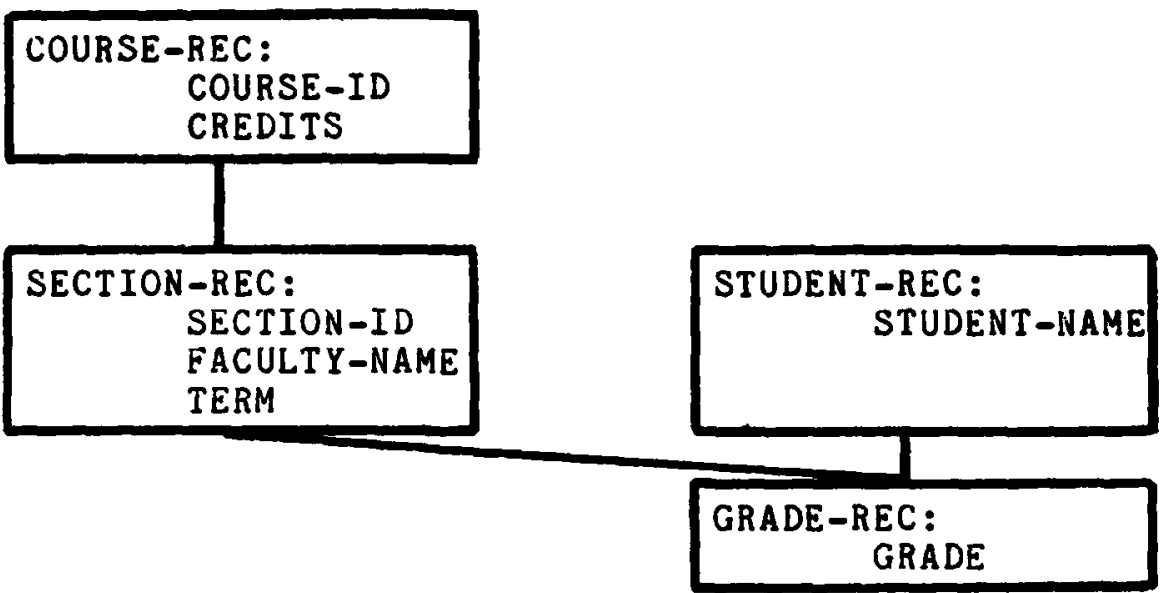

At the external or subschema level users should not see $\therefore$ networks but rather the hierarchies required for their Individual applications. In fact, where possible the uetails of the conceptual schema, its record types and set associations, should be hidden from the user. Navigation, uata association made using DML statements exploiting set membership, is only slightly removed from manipulation using record keys or device addresses. Such navigation should not ve necessary. Rather, subschema records should be in direct correspondence, not with schema records, but with the cognitive structures used by programmers in the solving of problems and the design of algorithms. Thus a SIUDENT-TRANSCRIPT subschema record would be a single record comprising student name and a repeating group containing course, grade, and term data; the user would request this record with a single DML statement, although it may correspond to dozens of schema records, of four record types, linked by membership in three sets.

The design limitations of the CODASYL subschema facility have undeniable implications for the process of application program development, maintenance, and execution.

1. Because the subschema structures are in close correspondence, not with user cognitive structures, but with structures provided for the complete enterprise data model, considerable user navigation is required to make necessary data associations and to construct the relevant information objects. This process is difficult, slow, and prone to error; obviously programmer productivity is affected.

2. In the CODASYL model, changes or extensions to the set of supported applications may well result in major structural changes to the schema; e.g., addition of a new application may change a schema 
nierarchy to a confluency. Because of the close correspondence between schema and subschema records, the application programs are not buffered trom this change, and thus may require major redesign and reprogramming effort. Horeover, the semantics of existing data associations, made by UML accesses and host language iteration and qualification, are very difficult to determine from the programs. Redesign will not be an easy, automated process; rather it will be manual and aifficult. Obviously, $\cdots$ data independence is affected [21].

3. Again, because of the level of CODASYL DML and the close relationship between schema and subschema, a number of data selection procedures (e.g., ignore records with the following data values) and data reduction procedures (e.g., return only average balances, grouped by class and status of account) are performed by the application programs. specified in the schema to subschema map, these procedures could be performed by a "data base machine" supporting the DBMS, rather than by the user program, substantially reducing the volume of data actualiy returned to the user program. Thus, channel traffic and communications expenses in a aistributed environment are affected.

10 make concrete the terms and objections stated, we consider as an example a data base again containing student course information. In the schema we have student records ielated to grade, course, and section grades as fellows:

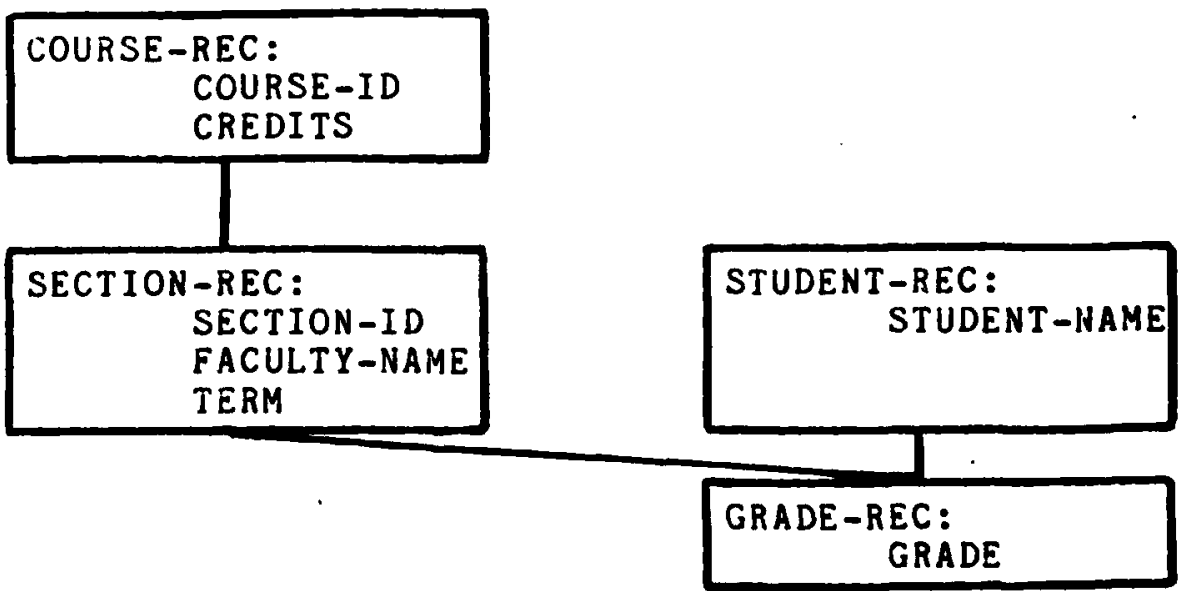

rom this we want to construct a summary transcript, with student name, average grade point, and average grade point 
Lor each term:

\&

\&

$\therefore$

(

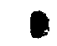

With an external schema facility, retrieval of this uranscript is requested with a single READ; changes to the conceptual schema structure that change record types and associations alter inter-schema mapping functions but not application programs; and in a distributed environment the aata base machine can transmit the desired summaries, rather ... the grade and course credit and term information needed wo compute these summaries. Also, we note that employing une current DML to compute these summaries, the user must:

1. FIND all GRADE records for a student

2. for each GRADE, FIND and GET the owner SECTION record

3. sort SECTION records in ascending order by term

4. make each SECTION record current, in order by term

2. for each SECTION record, as it becomes current, FIND and GET the owner COURSE record to get credit information. Also, for each current SECTION and the desired student, the member GRADE record must again have a FIND and GET to get the actual grade received.

6. with the information obtained in the preceding step, host language arithmetic statements are used to compute the desired averages.

clearly, obtaining the information with a single READ is preterable.

\section{AN ALTERNATIVE EXTERNAL SCHEMA FACILITY}

It is of limited usefulness to criticize a system design, without proposing an alternative. As an alternative, I offer a greatly enhanced subschema facility, ulle that in effect offers each user a virtual data base with simple structure corresponding to the specific needs of each application program. 
Such a facility has three basic requirements. To construct schema to subschema maps it is necessary to specify:

1. access information

2. restructuring information

*

3. data item definition

Access information specifies from which records data are to be obtained, what data values are necessary for qualification, and which set membership or other access paths are to be employed to make the necessary associations. restructuring information controls repetition $(\mathrm{e} . \mathrm{g} .$, the inclusion of all term summaries in a single summary cranscript in the example of section II), grouping (e.g., grouping of grade information by the term that the course was taken), and whether complete content or summary only data are to be included (e.g., include only summary over-all average and term averages, but no individual course grades). -ata item definition includes specifying the source of data L tems actually present in the schema, as well as rules for preparing virtual computed items and structured items. A aetailed description of such a general external schema acility for a relational environment is available [7]; Language enhancements for a CODASYL system are in preparation [11]. Such a facility will greatly simplify the programmer's interaction with data base systems, while Leaving concern for enterprise support and machine etficiency to other schema levels, as is appropriate.

\section{A CANDIDATE FOR STANDARDIZATION?}

1 do not propose that any current research on external schema facilities be given serious study as a candidate for ndardization at this time. Several technical problems emain, requiring technical study; likewise, several questions concerning human factors design and performance remain unanswered. An efficient implementation of a general external schema facility appears difficult; naive approaches suffer from explosive growth of required secondary storage and machine processing time. Equally important, the problem of data base update in a multi-schema environment remains unsolved: surprisingly few maps from -onceptual schema to external schema are invertible, implying that for most user updates to data at the level of the user's virtual data base, corresponding changes to the stored data base cannot be determined $[5,8]$.

Perhaps the most important consideration in any language, interface, or architecture design is their effect on programmer performance, in particular programmer 
productivity and program correctness and ease of maintenance. There has been some interest in human factors study and some guidelines have been given [20]; some interesting experiments have been performed [16, 17, 22] but there has been no conclusive work produced.

1 estimate that resolution of technical design problems and human factors questions is two or three years in the Iuture; preparation of potential standards, based on this work, will require still more time.

\section{WHAT DO WE DO NOW?}

It is apparent that we cannot wait three to five years tor the adoption of national standards, but must act now. rerhaps it is more accurate to say that if we do not act rapidly, we will have lost the potential for rational unoice: sheer volume of existing implementations and $1 n$-progress conversions based on systems currently .....ercially available will dictate a standard.

Therefore, my suggestion made originally in section I appears reasonable: We should agree that any future standard for data base architecture must include the current LUDASYL DML and subschema facility in its programmer interface, permitting data base conversions to be planned and performed now. We should also agree that, after five years, the facilities for CODASYL schema, subschema, and עSDL schema will be re-evaluated, based on advances in the eas of external, conceptual, and internal schema research. rerhaps, as a result of these advances, CODASYL specifications will have only limited resemblance to current specifications. Or, perhaps, future standards will preserve wothing of the current CODASYL specifications beyond that which is explicitly included in the kernel.

1 believe that much additional research in the area of une conceptual schema is required. Recent work by Bachman and Daya [3], Chen [6], and Gerritsen and Lee [15] indicate the potential for representing data base semantics as well as structure in the schema,. Work on external schema lacilities, based on my own research cited earlier and the implementation results of the IBM System $R$ group [2] must continue, and must be subjected to human factors study and valuation. Work by CODASYL at the internal schema level will continue. It is to be hoped that the results of these separate efforts can be combined, within the framework of an ANSI/SPARC three-schema architecture, to produce a data base architecture appropriate to the needs of business and government in the decade ahead. 


\section{ACKNOWLEDGEMENTS}

I would like to acknowledge my debt to my colleagues at the University of Pennsylvania, Rob Gerritsen and Frank vermano, to my co-panelists at the fourth Very Large Data Base Conference, John Berg, Frank Manola, and Diane C. P. Smith; and to my co-participants at the N.B.S. Three-Schema Feasibility Workshops, particularly Don Chamberlin, Henry Lefkowitz, and Carlo Zaniolo. Their uninking has influenced my thinking. Obviously, biases, errors, and omissions in this paper are my own.

\section{REFERENCES}

1. "ANSI/X3/SPARC Study Group on Data Base Management Systems Interim Report 75-02-08". FDT--Bulletin of the ACM SIGMOD, Vol. 7, No. 2, 1975.

C. Astrahan, M. M. et al. "System R: A Relational Approach to Database Management". ACM Transactions on Database Systems, Vol. 1, No. 2, 1976, pp. 97-137.

3. Bachman, C. W., and Daya, M. "The Role Concept in Data Models". Proceedings, Third International Conference on Very Large Data Bases, Tokyo, Japan, Oct. 1977, pp. 464-476.

4. Berg, J. L. "Implementing a Framework for DBMS Standards". Unnumbered Working Paper, Institute for Computer Sciences and Technology, National Bureau of Standards, Gaithersberg, MD, Mar. 1978.

2. Bernstein, P. A. and Dayal, U. "On the Updatability of Relational Views". Proceedings of the Fourth International Conference on Very Large Data Bases, West Berlin, Germany, Sept. 1978, pp. 368-377.

U. Chen P. P.-S. "The Entity-Relationship Model--Toward A Unified View of Data". ACM Transactions on Database Systems, Vol. 1, No. 1, 1976, pp. 9-36.

1. Clemons, E. K. Design of a User Interface for a Relational Data Base, Dissertation, School of Operations Research, Cornell University, 1976.

8. Clemons, E. K. "An External Schema Facility to Support Data Base Update“. Databases: Improving Usability and Responsiveness, ed. Ben Shneiderman, Academic Press, New York, 1978, pp. 371-398. 
y. Clemons, E. K. "The External Schema and CODASYL". Proceedings, Fourth International Conference on Very Large Data Bases, Berlin, West Germany, Sept. 1978, p. 130 .

10. Clemons, E. K. "The CODASYL 1978 DDL Specifications: A Critical Evaluation". Decisions Sciences Working Paper in Progress, The Wharton School, University of Pennsylvania, 1978.

11. Clemons, E. K. and Germano, F. "Design of an External Schema Facility for CODASYL Data Base Management Systems". Decision Sciences Working Paper in Progress, The Wharton School, University of Pennsylvania, 1978.

12. "CODASYL Data Base Task Group April 71 Report". ACM, New York, 1971.

13. "CODASYL Data Description Language Committee Journal of Development", 1978.

14. Gerritsen, R. "Conceptual and Internal Schemas in CODASYL", Proceedings, Fourth Internation Conference on Very Large Data Bases, Berlin, West Germany, Sept. 1978, p. 131.

13. Gerritsen, R. and Lee, R. "Extended Semantics for Generalization Hierarchies". Proceedings, ACM SIGMOD Workshop, Austin, Texas, June 1978, pp. 18-25.

16. Kuhn, M. and Shneiderman, B. "Two Experimental Comparisons of the Relational and Hierarchical Database Models". IFSM Technical Report No. 31 , University of Maryland, Feb. 1978.

11. Lochovsky, F. and Tsichritzis, D. "User Performance Considerations in DBMS Selection", Proceedings, ACM SIGMOD Workshop, Toronto, Canada, Aug. 197\%, pp. $128-134$.

18. Manola, F. "On Relating the CODASYL Database Languages and the ANSI/SPARC Framework". Proceedings, Fourth International Conference on Very Large Data Bases, Berlin, West Germany, Sept. 1978, p. 132 .

19. Manola, F. "A Review of the 1978 CODASYL Database Specifications". Proceedings, Fourth International Conference on Very Large Data Bases, Berlin, West Germany, Sept. 1978, pp. 232-242. 
20. Shneiderman, B. Improving the Human Factors Aspect of Database Interactions". Unnumbered IFSM Technical Report, University of Maryland, Jan. 1978

21. Smith, D. C. P. "Conversion and the CODASYL Framework". Proceedings, Fourth International Conference on Very Large Data Bases, Berlin, West Germany, Sept. 1978, pp.133-134.

cc. Ihomas, J. C. "Some Psychological Issues in Data Base Management". Proceedings, Third International Conference on Very Large Data Bases, Tokyo, Japan, Oct. 1978, pp. 169-184.

23. Tsichritzis, D. and Klug, A. "The ANSI/X3/SPARC DBMS Framework Report of the Study Group on Database Management Systems". AFIPS Press, Montvale, N.J., 1977 . 


\section{DISTRIBUITICIT LIS'P}

Lepartnent of the Ravy - Office of iraval Research

Lata Ease ilanagenent Systens Project

Defense Documentation Center

(12 copies)

Cameron Station

Alexandria, VA 22314

Office of ilaval Research Code 102IP

Arlington. Virginia 22217

Jrfice of iaval kesearcin

Brancin Cffice. Chicago

536 south Clark Street

Chicago, IL 60025

iNew York Area Office

715 aroadway - 5th Floor

i.jew York, iNY 10ve3

Dr. A. L. Slafkosky

Scientific Advisor

Comnandant of the liarine Corps

(CoJe RD-1)

vasnington: ic 20330

Office of ilaval Research

Cocle $450^{\circ}$

Arlington, VA 22217
Office of Llaval Research

(2 copies)

Information Systems program

Code 437

Arlington. VA 22217

Office of iaval kesearch

Branch Cffice

495 Sunter Street

Eoston. i:A $\quad 6221 \mathrm{a}$

Office of :aval Research

Eranch Office. Pasadena

1030 East Creen 3trect

Pasadena. CA 911 lu6

Naval Research Laboratory

(6 copies)

Technical Information Division.

Code 2627

7ashington, D 2 : 375

Office of haval Research

Code 455

Arlington, VA 22217

Naval Electronics Laboratory Center Advanced Software Tecinnology Division Code 5200

San Diego. CA 92152 
:ir. Z. ii. Jleissner

iaval Snip liesearch and

Levelogment Center

Computation \& dathe.zatics Leyt.

Eethesja. I 20004

Mr. Kin B. Thompson

Technical Director

Information Systems Division

(OP-Y11G)

Office of Chief of Naval Operations

Vlasington. $D 20350$

Frofessor Onar ining

Columbia university

in the City of ivew York

Dept. of Electrical Engineering

and Compliter science

Lew York. IY $10 \mathrm{U} 27$

Comancier, ivaval jea Gystens Command Department of the Navy

washington, D.C. 20362

AITENTION: (PHS3E611)

Captain Richard L. Vartin, USi: Conmanding officer

USS Francis ilarion (LPA-249)

FFO inew York jy501
Cactain Grace 11. Hopper

NAICCid:IIs Planning Eranch

(OE-GlúL)

Uffice of Enief of xaval juerations

hashington. is 2.j350

Bureau of Library and

Information Science Research

Rutgers - ithe State University

189 College Avenue

se's Brunswick, iJ 68903

Attn: ir. Uenry Voos

Jefense itapping Agency

Topograpiric Center

AInis: Advanced Technology

Livision

Coce 4l3üg (ir. W. dullison)

65:30 Jrookes Lane

vas'uington, D.C. 26315

:ajor J.P. Fennell

beadquarters. larine Corps

ivashington. D.C. 20386

ATTENTIOA]: Code CCA-40

Professor i:ike Athans

Wassachusetts Institute of rechnology Lept. of Electrical ingineering and Computer science

77 iass. Avenue

Canbridge, in 02139 